Second International Congress Nikola Tesla - Disruptive innovation, Sava Center, Belgrade, 2 - 4 June 2017

Invited lectures, Session 1, June 2

\title{
Tesla's Hidden Holism
}

\author{
Miloje M. Rakočević \\ Faculty of Science and Mathematics, Department of Chemistry, Niš, Serbia \\ mirkovmile@mts.rs; $\underline{\text { mirkovmiloje@gmail.com; www.rakocevcode.rs }}$
}

\begin{abstract}
Today, without a doubt one can say that the work of Nikola Tesla has a lot of hidden ideas, as in the time when he created, and in the "postponed time", when later we research the documentations in his professional and scientific legacy. In addition to above, can be presented significant Tesla's records, which testify Tesla's holistic approach to the natural systems, through a higher degree of interdependence of parts within the whole, as well as the interdependence of each part of the whole to which it belongs. By this, the "higher level dependency" can be understood in the sense that a whole is not a simple sum of the parts and the relationships that it (the whole) make, but also for the relation of the parts to the environment, as well as the relation of the whole and connection to the environment, wherein the "environment", among other things, is a series of natural numbers, with its principles and laws; and that "others" are the principles of the organizing the Universal Code of Nature, which code will also be presented.
\end{abstract}

Keywords: Holism; Bohm; Smuts; Darwin; Darwin's Diagram; Mendel; Mendeleev; De Saussure; Linguistics; Whole and Parts; Golden Mean; Language; Genotype; Phenotype. Plato; Aristotle.

We are talking in this occasion about Tesla's hidden holism, so the question arises, why this holism is hidden? The reason lies in the so-called current science, the fact that it deviated from the main eminents of science, Darwin, Mendel, Mendeleev, and De Saussure. [De Saussure was the founder of the structural linguistics and semiology that (both) in recent times, and with new understandings, are becoming more and more important not only in social but also in natural sciences]. And, without proper approach in science, without the proper and genuine understanding of these four classic authors, Tesla, especially his work, cannot be understood. With this different understanding, we will just deal in this presentation.

When we speak about holism, we must first mention David Bohm, according to whom the objective world is merely an illusion, like a holographic image (hologram), in the following sense. Within the depth of reality there is an implicate unpacked, an "enfolded" world, while this world we "see", is in fact an explicate, an "unfolded" world. This Bohm's hypothesis, in a certain way, corresponds to Plato's notion of the world of ideas. However, the extent to what Bohm is right and how much he is not, it remains for consideration at some other occasion, and here we refer to him only for the purpose of presenting and differing understanding of holism, in relation to Tesla's holism, which is the subject of our consideration.

For the same reasons we also mention one other advocate of the idea of holism, Jan Christiaan Smuts (1870 - 1950), a researcher in the field of social sciences, a former South African marchal and prime minister. He primarily dealt with the problem of the holistic organization of society, especially the military. In the later years his books are reprinted. [Smuts' book Holism and Evolution from 1926, was reprinted in 2013. The reason for the actuality of the book is probably that it criticizes partialism and disparity in the overall science, but also in society.] Smuts returns to Aristotle insisting that the key to understanding the construction of any system, natural and/or social, is that the whole is more than a collection of parts. 
My approach to understanding of Tesla's holism is different. In the two previous essays, ${ }^{1}$ I tried to give a valid argumentation that Tesla's holism is the same as in Njegosh's work - "the general accordance", a universal connection and interdependence in nature, in the sense that any functional and sustainable natural system was built so that it was determined by the best possible symmetry, proportion and harmony. Hence, about any such system it makes sense to speak as of a code, in fact about an aspect of the universal code of nature, as a kind of realism of holism. ${ }^{2}$

According to the "general accordance" model - the universal code of nature - from the time of Plato's idealistic to Smuts's holistic state, many theoreticians of social sciences, statesmen and politicians contemplated the possibility of creating an ideal state (and society), but, as we know, it has not succeeded so far. However, the failure of the statesmen and philosophers was overcome by the artists. Musicians, poets and painters (also creators in applied arts, especially in architecture) managed to create such works that by their structure and composition, and sometimes by contents - through modeling and metaphoricity - simulated the harmony of natural systems. Tesla, although he dealt with engineering and practical work, tried his best to do so all his work, writing and speaking. Therefore, when it comes to Tesla, it cannot be bounded only within the limits of science and engineering, but also philosophy, art, even religion must be included.

Only with such an approach we can understand Tesla's articles, some of which at first seem to be naive and/or utopian. First of all, this refers to Tesla's 1900 article "The Problem of Increasing Human Energy". At the end of this article, he almost gave the solution of the enigma, trying to indicate that he, Tesla, dealing with science and engineering, is also concerned with art all the time. Namely, he became directly to be a supervisor of the printing of the corresponding issue of the prestigious American The Century Magazine, that at the very end of Tesla's article, had been Goethe's verses that talk about human hope. Together with the poet Tesla hopes that along with the general harmony will come the time and universal human well-being, ${ }^{3}$ he also repeated on many other occasions: "In one lecture I held at the American Institute of Electrical Engineers at the University Columbia, on May 20, 1891, I said: "We are swirling through an infinite space with incalculable speed, everything around us is moving around, everything is moving, energy is everywhere. There must be some way to start to use that energy more directly. Then, with the light that we receive from that medium, with the energy derived from it, with every form of energy that is obtained without effort, from the inexhaustible man's warehouse, mankind will advance with giant steps."' (Tesla, 2006, pp. 332, in relation to Fig. 1).

I propose three Tesla's records, which, in my opinion, testify that Tesla all natural systems, and also the overall reality, perceived holistically as a higher degree of interdependence of parts within the whole, as the interdependence of each particular part and the whole to which it belongs. In doing so, a "higher degree of interdependence" is understood in the sense that the whole is not a mere sum of the

\footnotetext{
${ }^{1}$ The first essay was published in the paper (Rakočević, 2006) under the title „About Tesla's 'trinity' and Njegosh's 'sixth'“, while the second was published in the work (Rakočević, 2007) under the title „About Tesla's and Njegosh's general accordance."

${ }^{2}$ In our approach to Tesla's work, it was necessary to include ideas about the universal code of nature, whose aspects are genetic and chemical code, and natural language. Furthermore, it was possible to show (in my researches) that the classics of literature - Homer, Dante, Shakespeare, Gete, Pushkin, Njegosh, Tolstoy - created their works by incorporating a strict mathematical language, which "shows" that the relationship of parts within the whole is determined by the best possible symmetry, proportion and harmony; in other words, it is determined mathematically strictly (or almost strictly) by both harmonic mean and golden mean.

${ }^{3}$ Tesla (2006, p. 156): "Creation and destruction of a material substance, its association in forms to our own will, this would be the ultimate manifestation of man's reason, his most complete triumph over the physical world, his crownful achievement that would put him alongside of His Creator and fulfilled his final destiny."
} 
parts and their relations (within the whole), and also the relation of parts to the environment, as well as the relationship of the whole and the connections to the environment; the environment including among other things, the series of natural numbers, with their principles and laws.

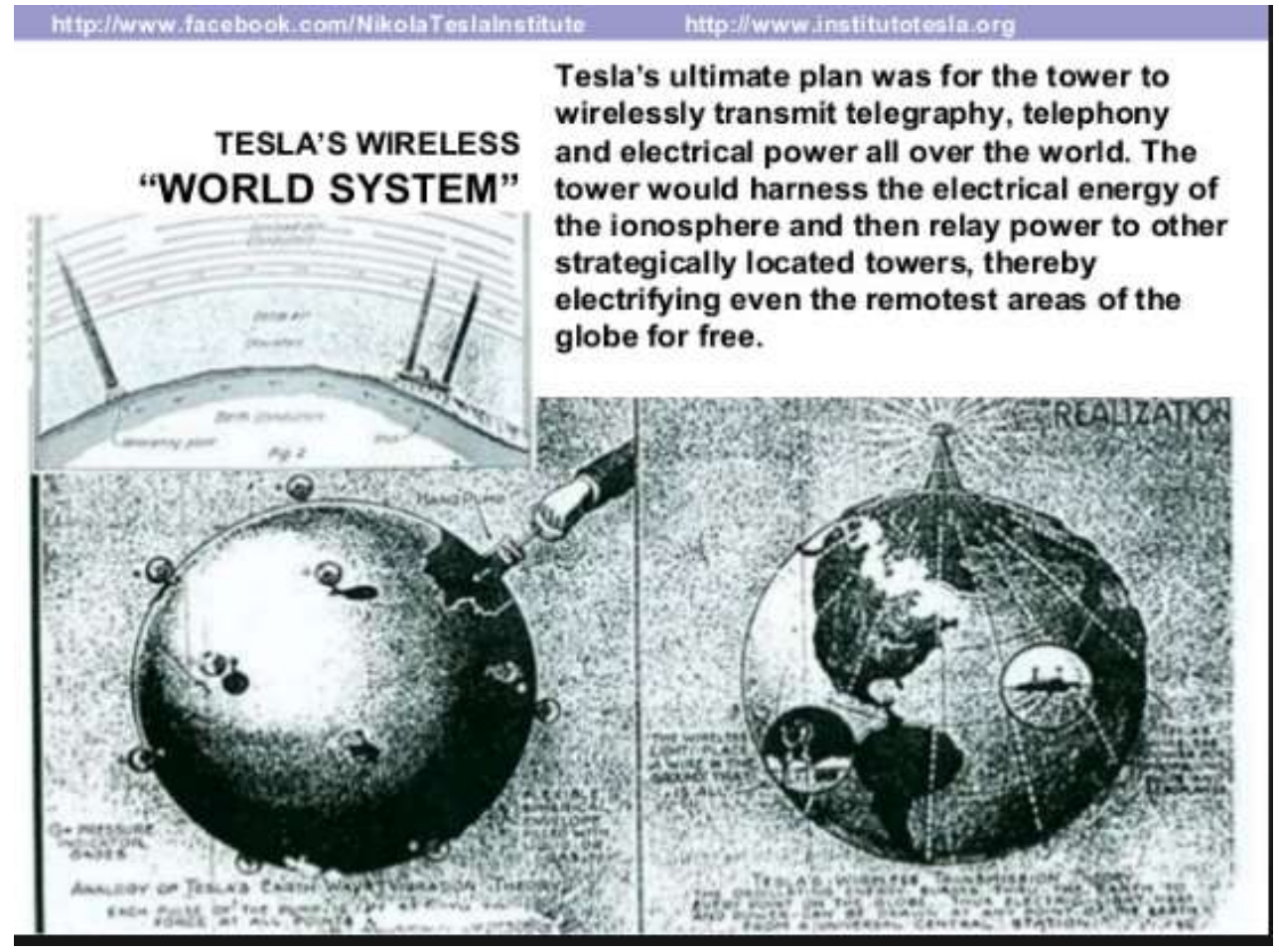

Figure 1. The modeling of the Tesla's global wireless power transmission system

The first Tesla's record is from his article "How the cosmic forces influence our destiny" (Tesla, 1915), and concerns Tesla's conviction that "the field of external influence is expanding ... indefinitely" to everything and everyone, within the whole universe (Record 1). The second Tesla's record is from his essay My Inventions (Tesla, 1919), and concerns Tesla's determination and limitation of an object in relation to the "environment" (Record 2). And particularly significant in this record is Tesla's testimony that "all acts and actions", which he repeatedly "repeated", "had to be divided with three." This significance stems from what we know today that the number three, as half of the first perfect number, is the determinant of the unity of perfection and symmetry, ${ }^{4}$ and also the determinant of the symmetry of the Multiplication Table in any numbering system. ${ }^{5}$ Hence, regardless of whether all these relations seemed consciously, unconsciously and/or subconsciously, they were Tesla's real "acts and actions", whose form we can now recognize as a hidden holistic approach in understanding things-processesphenomena (Record 3).

\footnotetext{
${ }^{4}$ In fact, the number three is a half of number 6 which is the most perfect number, because it is the only one of all the perfect numbers, which represents the sum and product of the three adjacent numbers - the first three natural numbers: $1+2+3=1 \times 2 \times 3$. In addition, regarding symmetry, it refers to "the symmetry in the simplest case on the real line" (Marcus, 1989).

${ }^{5}$ If the numerical basis of a numbering system has $n$ digits, then the "symmetry space" of the Multiplication Table in that numbering system occurs by starting the multiplication with $n / 2$. By multiplying with 1 , we find the half of the scale of $n$ digits; multiplying by 2 , we are at the end of the scale, and only by multiplying with 3 , we "descend" from the scale.
} 
The third Tesla's record is about his essay, which I mentioned at the beginning of this exposition: The Problem of Increasing Human Energy (Tesla, 1900) (Record 4). From the many ideas contained in this more than interesting essay, we single out here only one: the idea of a possible correspondence of the mathematical expression for kinetic energy with the golden mean. If the formula for kinetic energy is written in the way Tesla did, then such an understanding of the formula makes sense. In the article, namely, Tesla explicitly says: "In accordance with the previous, human energy is obtained by the product $1 / 2 \mathrm{MV}^{2}=1 / 2 \mathrm{MV} \times \mathrm{V}$, where $\mathrm{M}$ is the total mass of a man in the ordinary interpretation of the word "mass", and V is a certain assumed velocity in the present state of science, we are not in a position to precisely define and establish". [It is important that, in our time, there are efforts to define this Tesla's velocity, its relationship with "ordinary", as well as with the possible "codogenous mass" (Record 5).]

Record 1. Tesla (2006, pp. 147-148): ${ }^{6}$ "Every living being is a machine connected to a wheel of the universe. Although only its immediate surroundings affect the look on it, the field of external influence extends indefinitely. There are no constellations of stars or nebula, the Sun or the planet, in the depths of unlimited space, nor the starry sky storms, which in some way do not affect his fate - but not in the vague and misleading sense of astrology, but in the unshakable and reliable sense of natural science. ... Therefore, everything that exists, organically or inorganically, alive or not, is sensitive to external irritations. There is no limit, no interruption of continuity, nor a specific and determined initiator of life. The same law governs the whole matter, the whole universe is alive". ${ }^{7}$

Record 2. Tesla (2006, p. 24): "I counted the walking steps, ${ }^{8}$ calculated the volume of the contents of a plate of soup, a cup of coffee and a piece of food - otherwise I could not enjoy the meal. All the actions and procedures I repeated had to be divided with three, and if I were wrong, I was forced to start everything from the beginning, even if it took several hours for it; " Jerotić (2006, p. 3): "He chose room 207 (the number is divided by 3), and the attendant ordered that he leave 18 towels every day. He dined exactly at eighteen o'clock, and on the table was, as usual, 18 linen napkins"; Trebješanin (2006, p.13): "In his autobiography, he mentions his "strange affliction", the unusual images that he had seen and the visions that raised against his will when he was a boy"; ibid., p. 16: "Tesla, at an early age, discovered ... his unusual power of imagination, could easily, by his will, cause scenes of unknown places, beyond the boundaries of his known world."

Record 3. Raković (2006, p. 420): "The Tesla's testimonies unambiguously indicate that Tesla's visions and discoveries are realized in controlled altered and transitional states of consciousness, which are manifestations of macroscopic quantum nature and non-locality of consciousness, with significant psychosomatic-transpersonal and cognitive-creative implications. ... Today's fundamental research of consciousness (indeterministic properties of free will, holistic manifestations of transitional states of consciousness and altered states of consciousness, conscious-unconscious transition, and non-local properties of consciousness pervading body) necessarily indicate

\footnotetext{
${ }^{6}$ The three Tesla's records that we refer here are translations of translations of his original works, published in the American journals listed on the relevant page in References (Tesla, 2006).

${ }^{7}$ If we want to interpret Tesla's statements correctly and accurately, then in the last sentence, the logical trail is: the "whole universe is alive" follows from the fact (according to Tesla) that "the same law governs the whole matter". Therefore, Tesla does not joke here, nor does he deal with metaphors, but he realizes that life per se is incorporated in the matter. If today we know that both basic natural codes - chemical and genetic code - follow from the same mathematical expression (Rakočević, 2017, Survey 3, p. 14), no further comment is needed.

${ }^{8}$ This syntagm is almost completely identical to the famous Njegosh's syntagm about steps and space when he talks about the Creator's creativity ("Steps my are godly / I can call them space" - Njegosh, Luča, III, 149-150), and this creativity comes into conjunction with the poet's work ("... the son of Nature - the poet, the Little Creator, the closest to God"). Obviously, both the thinkers (Tesla and Njegosh) see creativity as an embodiment of a "general accordance"; both of them see that we live in the Universe in certain steps and space, in a way that may, perhaps, remain an eternal puzzle (Velimirović, 1987, p. 9: "The puzzle of Nature is the first thing that a man finds himself, when he stirs his eyes and look in this great world").
} 
that some manifestations of consciousness must have a deeper quantum origin. In addition, practical and convincing demonstrations of the model application of quantum-holographic Hopfield neural networks for superior image recognition ... indicate that quantum-holographic information laws appear as structural-invariant characteristics of each quantum system, reminiscent of similar ideas of the general theory of the system applied to biological systems, and may also be associated with the known open problem of "emergent control" (also known as downward causation) of higher hierarchical levels over the lower ones in cognitive science."

Record 4. Tesla (2006, pp. 93-95): "When we talk about man, we mean the concept of mankind as a whole, and before we apply the scientific methods in examining his movement, we must accept this as a physical fact. ... Each of us is just one part of the whole. For centuries, this idea was proclaimed in the perfectly wise teaching of religion ... We are all one. Metaphorical evidence, ${ }^{9}$ however, is not the only one that we can take to support this idea. Science also recognizes the connection of individuals, though not quite in the same sense as recognizing that suns, planets, moons, constellations are the one body, and there is no doubt that this will be confirmed by experiments in the future. ... Even more: This one human being continues to live. .. Imagine then a man as a mass driven by force...."10

Record 5. Koruga (2007, pp. 31-52): „The difference that exists between the velocity of the Sun and the velocity of the object on Earth moving by the ellipse around the Sun is Tesla's "hypothetical velocity" which primarily determines the state of the "codogen mass" on Earth ... The difference between ordinary $(m)$ and "codogen mass" ( $M$ - "Mass representing Man") is in possession of a potential or active information content encoded at the nano (molecular) level. For example, water in the cup, and the same amount of water in the human organism are of two different masses: in the first case it is an ordinary mass $(m)$, while in the second one, as an integral part of biomolecules, it is the "codogen mass" $(M)$, which in the dynamics of biomolecules also realizes information content ... Another important feature of "codogen mass" is its duality, because its velocity $v$ belongs to the Sun, and the velocity $\mathrm{v}^{*}$ belongs to the Earth. Having in mind the research result that showed that the DNA was determined by the golden mean ..., then, the "codogen mass" on the Earth can function by the principles of icosahedron or dodecahedron, because only these two bodies are dual with golden mean properties. It can be said that the icosahedron "codogen mass" is on Earth, and the dodecahedron one in the Sun."

We see that Tesla's formula for kinetic energy is written in a way that we will not find anywhere else. Namely, the question is why he needed to bring the square in the expression for speed to linearity, since the speed (some " $\mathrm{x}$ " in the general square equation) is written in the form "V $\mathrm{x} \mathrm{V}$ ". In my judgment, by writing "MV x V", Tesla wants to point out that this is the relation of a greater part towards the smaller (within a whole), which is then inevitable a relation to golden mean. ${ }^{11}$ Namely, in the case of $M=1$, we have two equal expressions: V/2 and V/2, which, in the case of dividing the unit length into two parts, are reduced to the zeroth case of the generalized golden mean (Stakhov, 1989;

\footnotetext{
${ }^{9}$ Popovic (2010, page 428): "Metaphor (gr. metaphor - transfer) is a stylistic figure in which one object or phenomenon is described by another, similar to it ... Modern theory determines [metaphor] as every coherent use a word that is not literal."

${ }^{10}$ In addition to other hidden ideas, here is the idea of the necessity of using metaphor (humanity as only one human being) in a strict scientific research, and not just as a stylistic figure in literature. So far it was thought that the work of Clements in 1916 was the first such work, and now we see that it is not, but this is Tesla's work. [Frederic Edward Clements (1874-1945), born in the United States (Santa Barbara, California) is best known for his theory of community life development; more precisely, by the theory of herbal successions. He found that one plant community is going through a predictable series of developmental phases that can be adequately compared with the development of one organism (the metaphor adequacy!). In other words, one living community is a "complex organism" that has its own unique physiology that can be studied with the same precision as the physiology of an organism in a laboratory.]

${ }^{11}$ Something similar is found in Aristotle: "... intuition is the principle of the principle itself, and the whole science refers to the whole of things as intuition refers to the principle" (Aristotle, 1970, p. 359).
} 
Rakočević, 2004). In this way, Tesla tries to present once more the generality, interdependence and perversity, which we can understand today as a kind of holistic approach in understanding reality as such. ${ }^{12}$

The question arises, from the beginning of this expose, whether all of these Tesla's quotations, and statements about Tesla's sayings, as well as all Tesla's numbering actions and spatial scattering, can be made clearer and more comprehensible when viewed in the light of the necessary critique of the mentioned deviation of the current science of the coryphaeus of systemic approach in the study of fundamental natural phenomena.

First of all, I present the key deviation from the science of Mendeleev. Already in primary school chemistry textbooks we encounter the wrong Table of the Periodic Table of Chemical Elements (PSE). It is termed as if all 14 lanthanides are in the third group, where it is also lanthanum. If this were so in Nature, and in the nature of things, then what is with the Mendeleev's principle that every uneven element must be in uneven, and each even in even group. Excluding this fact, we also exclude the necessary correspondence of the sequncing of chemical elements with the sequncing of the series of natural numbers. In such a case, of course, the Tesla's counting of the steps become to be meaningless, as Njegosh's space-steps are losing of their divinity.

It is the fact that in Mendeleev's Archive there is the PSE Table, which Mendeleev made partly by his own hand, and partly by the press machine, in 1900, seven years before his death. In this Table, lanthanum is really in the third group, but the next element, the first lanthanide, the Cerium, the 58th in the order of the even elements, is not in the third (uneven) than in the fourth (even) group. Mendeleev then outlined the positions of 13 lanthanides, with the predicted their atomic masses, also for those two elements that were unknown to his life. [Following this idea of Mendeleev, the 27 years ago I presented the reality of the periodic system in which each lanthanide is in a separate group (Rakočević, 1991; 1997) ${ }^{13}$. In the recent time I have also realized that this and such a PSE derives from a single mathematical expression (Rakočević, 2017, Eq. 1, p. 6).]

Let's see what is the departure from the first eminent of genetics, Gregor Mendel. In 1909, Danish scholar Wilhelm Johannsen, except that he (rightfully) introduced the term (and notion) gene into genetics, he introduced (ill-founded, that is, deviating from Mendel) two more concepts - genotype and phenotype. In his one and only original article, Mendel, however, speaks of four entities: 1. Parent pair (which, at the cytological level, is reduced to the zygote), 2. Constant forms, 3. The number of knees and 4. The number of individuals. What is especially interesting is the fact that for each of these four entities, the corresponding mathematical expression was given by the fact that these four numbers $(1,2$, $3,4)$ are given with the power of the general number $n\left(1^{\mathrm{n}}, 2^{\mathrm{n}}, 3^{\mathrm{n}}, 4^{\mathrm{n}}\right)$.

Only recently, when the human genome was deciphered, and viewed that the epigenetic changes (the influence of the environment) are far more significant in inheritance than previously thought, it was also seen that the "too narrow" formula was given by Johansen; that the phenomenon of heritage cannot be reduced to only two entities. In other words, it seemed that a more adequate model had to be sought. In my opinion, there is no need to look for anything new, but return to the very source, to what Mendel suggested.

12 It is interesting that brothers Sinisha and Sasha Rudan (whose statements are also contained in this Proceedings), completely independent of me, also dealt with this problem. They noticed, in fact, that this Tesla's otherwise written term for kinetic energy, has to do with the golden mean.

${ }^{13}$ In the book (Rakočević, 1997), PSE Tables are added at the end of the book, and this book can be also found on my website. There are three Tables: the PSE Ttable of short periods, then the Table of long periods, and the third Table with six groups, analogous to the first Mendeleev's Table (1869), which also had six groups (Mendelejeff, 1970). 
Now we are going to the problem of deviation from Darwin. In his book Origin of Species, from 1859 , there is only one single illustration, his famous Diagram of evolution. The 17 years ago in one of my books, published in Belgrade in English, I have noticed that this is not an ordinary diagram, an ordinary illustration, but that is a rigorous mathematical program embedded in Darwin's Diagram. By others, in that program is, mutatis mutandis, included the same formula we find in Mendel. [We found the same sequence $\left(1^{\mathrm{n}}, 2^{\mathrm{n}}, 3^{\mathrm{n}}, 4^{\mathrm{n}}\right)$ where $\mathrm{n}=2$; see in paper: (Rakočević, 2015, Figure 7, page 29).]

The problem of deviation from Ferdinand de Saussure is in the next. De Saussure says: In any language of the world, only four of types are possible from the aspect of generating of votes. If they are generated in the oral cavity then they are "les sons sourds"; if in the throat, then they are "les sons sonores"; and two more types - "les sons sourds nasalisés", and "les sons sonores nasalisés". We see that there are two laws of the logical square here; first, to be 2 and to be 2 once more; and the second law: to be to be 1 and 3. The basic, zeroth type are sourds voices, and the remaining three types are deviations from the zeroth case, so they are no longer only sourds.

All this what is valid for voices can be applied to accents. For example, in Slovene languages: two accents are ascending, two descending; two are short and two long. It is even easier to see the validity of this second law of the logical square, which means being 1 and 3. It is only a descending accent fast and the remaining three are slow.

All that is true for voices in natural spoken language, analogically applies to genetic code. Three of the same small molecules (cytosine, adenine and guanine) participate in the construction of macromolecules of DNA and RNA, and one different in addition, thymine and uracil, respectively. It is taken as if it were an alphabet, a four-word alphabet, from which the three-word words are generated. Naturally, they must be 64 . But the relations of these four small molecules, in terms of chemistry, are actually reduced to the relationships of a logical square. Two molecules are single, i.e. single-sided, while two molecules are double-sided. On the other hand, two simpler molecules (uracil and adenine) interconnect with two hydrogen bonds, and two more complex molecules - cytosine and guanine - with three hydrogen bonds. Hence, the law of the logical square also applies here: two and two and another two and two. Two molecules are simpler, and two are more complex; two are bound by a weaker chemical bond, and two are bound by stronger chemical bonds. But there is also the second law - to be 1 and 3. Only uracil (or thimin) contains two oxo groups, while the remaining three contain at most one. On the other hand, only adenine does not contain an oxo group, while the remaining three contain at least one at a time. ${ }^{14}$

The answer to the question raised whether Tesla's statements can be made clearer and more understandable after the necessary critique of the deviation of the current science from the corpus of systemic approach in the study of fundamental natural phenomena is now more than certain - this answer is affirmative! With this knowledge, we go back to the "problematic" Tesla article from 1900 and read it again from the very beginning: "Of all the diverse phenomena that nature provides to our senses, none of them fills us with greater amazement than this extremely complex movement, which in its entirety is defined as human life ... Although we may never be able to understand human life, we certainly know that - that is the movement, whatever it is. ${ }^{15}$ The existence of a movement inevitably means the existence of the moving body and the power that moves it. Accordingly, wherever there is

\footnotetext{
${ }^{14}$ The validity of the two laws of the logical square is already found in Aristotle. In the building of the Universe, Aristotle spoke, there are four "elements": Earth, Water, Air and Fire. In addition: the two are wet and two are dry; two are cold and two warm. But there exists also the second law of the logical square: only the "Earth" is thick, while the remaining three are non-thick. On the other hand, only the Fire is of a "phenomenon", and the remaining three are "substances".

15 "Life is movement" (Aristotle).
} 
life, there is also a mass driven by a force. Every mass has the force of inertia, every force tends to be kept. Because of this universal character and state, the bodytend to remain in the same state of movement, and the force, manifesting itself everywhere and for any reason, creates an equal opposite force, and so arises the absolute necessity that every movement in nature must be rhythmic ... It is born in everything we see - in the movement of one planet, high and low tide, in the reflection of air, in the movement of the pendulum, the oscillations of the electric current, and in extremely different phenomena of organic life. Does not this confirm the entire human life? The birth, growth, age, and death of an individual, family, race, nation, what if it is not a rhythm? "(Pp. 91-92).

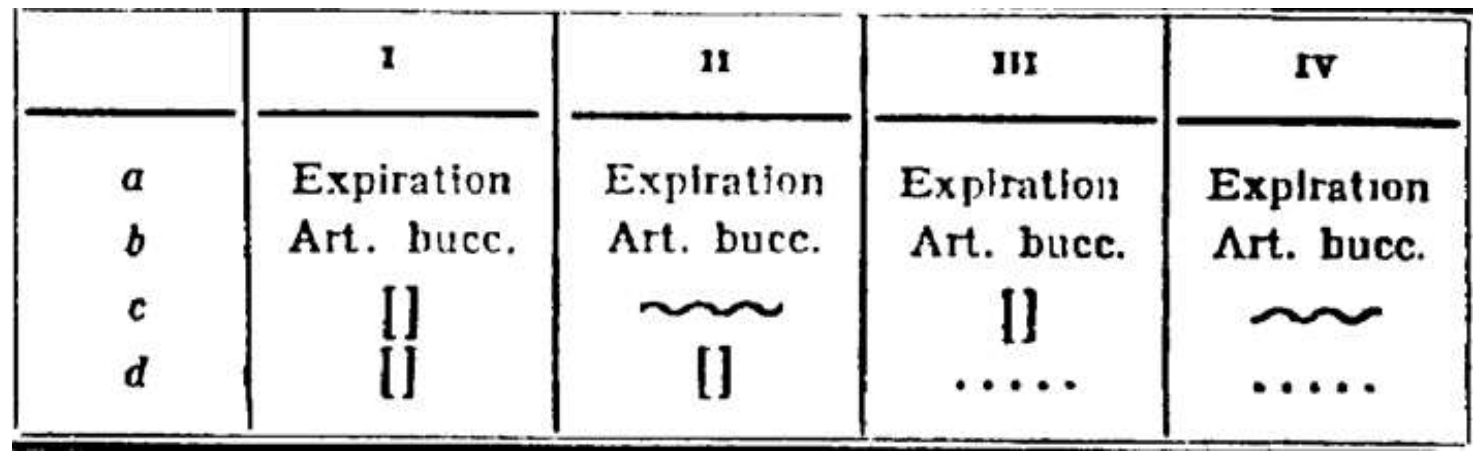

Figure 2. Principles of phonology. Possible variations in generating four types of voices in any language in the world: a. Expiration, b. Art. bucc. of phonemes, c. Triller of the throat, d. Nose Resonance. I. les sons sourds (binary record: 00), III. Les sons sourds nasalisés (01), II. Les sons sonores (10), IV. les sons sonores nasalisés (11) (de Saussure, 1985, p. 70; de Sosir, 1989, p. 56). From the aspect of the binary record in which "0" signifies a lower, and "1" a higher level, this model applies to all types of logical squares, interpreted within this paper.

Yes, indeed - to repeat Tesla's words - every movement in nature must be rhythmic. And to be rhythmic, it is, mutatis mutandis, in relation to the golden mean and the generalized golden section; then, with the $n$-th ranked Mendel sequence of the inheritance $(1,2,3,4)^{16}$, with Mendeleev's periodic system in which the chemical elements go in the "consensus" with the series of natural numbers; with natural-coded sequences in the Darwin's diagram, in the same way as with the natural-voice-codogenic sequences in de Saussure's graphical representation of the generation of voices in any spoken language in the world (Fig. 2). In other words, understanding Tesla's work requires a true way of searching for a scientific truth, in a true time, which in no way will be overwhelmed by any ideology, personal and other interests and politics. ${ }^{17}$

\section{References}

Aristotle (1853) The Organon, H. G. Bohn, London; there is also Serbian translation.

Bohm D. (1980) Wholeness and the Implicate Order, Routledge \& Kegan Paul, London.

Clements F.E. (1916) Plant Succession, Carnegie Institution, Washington.

Darwin C.R. (1859) On The Origin of Species, John Murray, London; there is also Serbian translation.

De Saussure, F. (1985) Cours de Linguistique Generale, Payot, Paris; there is also Serbian translation.

\footnotetext{
${ }^{16}$ This is a heritage formula, corresponding to integrativism, not to reductionism with only two entities - genotype and phenotype.

${ }^{17}$ I am sure that one future analyst of century-stepping will discover that the time of the second half of the twentieth and beginning of the twenty-first century is characterized by arrogance and ignorance of the "invited" and self-proclaimed powerful in all areas of human action and life, by whose omnipotence, according to the words of the Nobel Prize Jose Saramago, the universal lie replaced the multimeaning truth.
} 
Jerotić, V. (2006) Psychological portrait of Nikola Tesla, Književnost 2, 3-12 [in Serbian].

Johannsen, W. (1909) Elements of an Exact Theory of Heredity, Gustav Fischer, Jena [in German].

Kedrov, B.M. (1977) Predictions of Mendeleev in Atomism - Unknown Elements, Atomizdat, Moscow [in Russian].

Koruga, Dj. (2007) Tesla's „hypothetical veocity“: phenomenon of life and synergy of classical/quantum actions; in Proc. Tesla - Visions, Work, Life, 31-52, Faculty Mech. Engin., Univ. Belgrade [in Serbian].

Mendel, J.G. (1866). Experiments in plant hybridization, Proc. Brünn Natural History Society [in German].

Marcus, S. (1989) Symmetry in the simplest case: the real line, Comput. Math. Appl. 17, 103-115.

Mendelejeff, D.I. (1970) Zeitschrift für Chemie 12, 405-406, 1869. Reprinted in D.M. Knight, ed., Classical Scientific Papers--Chemistry, Second Series, 1970; translation from German by C. Giunta.

Plato (1908) The Republic, Clarendon, Oxford; there is also Serbian translation.

Popović, T. (2010) Dictionary of Literary Terms, Logos Art, Belgrade [in Serbian].

Raković, D. (2006) Nikola Tesla - understanding the nature of creativity (on behalf of Tesla's 150 birthday anniversary), Stil 417-426, Belgrade [in Serbian].

Rakočević, M.M. (1991) The coherence of the chemical and genetic code, Proc. Faculty Sci. (former: Faculty Philos.), Chem. Sect. 2, 1-29, Niš, Serbia.

Rakočević, M.M. (1997) Genetic Code As a Unique System, Studentski kulturni centar - Niš \& Bina Belgrade, Serbia (http://www.rakocevcode.rs).

Rakočević, M.M. (2004) Further generalization of Golden mean in relation to Euler's „divine“ equation, FME Trans. 32, 95-98, Faculty Mech. Engin., Univ. Belgrade. Also in arXiv:math/0611095 [math.GM])

Rakočević, M.M. (2006) About Tesla's 'trinity' and Njegosh's 'sixth', Faculty Techn. Sciences \& Society Scient. Popular., Univ. Novi Sad [in Serbian].

Rakočević, M.M. (2007) On Tesla's and Njegosh's general accordance; in Proc. Tesla - Visions, Work, Life, 73-98, Faculty Mech. Engin., Univ. Belgrade [in Serbian].

Rakočević, M.M. (2015) Enigma of Darwin diagram, www.rakocevcode.rs, stored on 2015-01-06. Also stored in: OSF Preprints, 2017-11-29 (UTC); DOI 10.17605/OSF.IO/QZG69.

Rakočević, M.M. (2017) Analogies of genetic and chemical code. www.rakocevcode.rs (stored also in: OSF Preprints, 2017-10-07, DOI 10.17605/OSF.IO/MXECJ).

Rudan, S., Rudan, S. (2017) Personal communication.

Smuts, J.C. (1926) Holism and Evolution, Macmillan, New York.

Stakhov, A.P. (1989) The Golden section in the measurement theory, Computers Math. Applic. 17, 613-638. Talbot, M. (1991) The Holographic Universe, HarperCollins, New York; there is also Serbian translation. Tesla, N. (1900) The problem of increasing human energy, The Century Magazine, June, 1900.

Tesla, N. (1915) How the cosmic forces influence our destiny, New York American, February 7, 1915. Tesla, N. (1919) My Inventions, Electrical Experimenter, February - October, 1919.

Tesla, N. (2006) The Papers, 2nd ed., Zavod za udžbenike i nastavna sredstva, Belgrade [in Serbian]. Trebješanin, Ž. (2006) Tesla's inclination to mystics, Književnost 2, 13-19 [in Serbian].

Velimirović, N. (1987) Njegosh's Religion, Glas Crkve, Šabac [in Serbian]. 